\title{
Reduction of Morphine During Baking? Response: Commentary: Opium Alkaloids in Harvested and Thermally Processed Poppy Seeds
}

\author{
Marcel Kuntz, Patricia Golombek and Dirk W. Lachenmeier* \\ Chemisches und Veterinäruntersuchungsamt (CVUA) Karlsruhe, Karlsruhe, Germany
}

Keywords: poppy seeds, Papaver somniferum, alkaloids, thermal processing, morphine, codeine, thebaine

\section{A Commentary on}

Commentary: Opium Alkaloids in Harvested and Thermally Processed Poppy Seeds by Kleinmeier, D., Pettengill, E., and Redan, B. W. (2021). Front. Chem. 8:622488. doi: $10.3389 /$ fchem.2020.622488

The article of Kleinmeier et al. (2021) points out a controversial issue in the scientific literature, namely the potential for reduction of opium alkaloids during thermal processing of poppy seed containing foods. Due to its toxic effects above certain thresholds as well as the potential for confounding drug tests for opiates (Lachenmeier et al., 2010), this question is of significant importance regarding acceptable levels for products intended for baking purposes. While previous literature has generally assumed a considerable decrease of morphine and other alkaloids during baking (Brenneisen and Borner, 1985; Kniel, 2006; Sproll et al., 2006, 2007; Carlin et al., 2020), new data from the U.S. Food and Drug Administration (FDA) (Shetge et al., 2020; also see discussion in Kleinmeier et al., 2021) has shed doubt on this opinion as opiate levels were quite stable when incorporated into a model baked product. Kleinmeier et al. (2021) tried to explain this discrepancy by the possible confounding of previous baking experiments by processing steps including soaking of the poppy seeds, which has been reported to reduce opium alkaloids on the surface of poppy seeds.

As our own previous study (Sproll et al., 2006) was specifically pointed out as being "confounded," we hereby want to take the chance to rebut this claim, and provide evidence that our study was not confounded by processing steps. The experiment of our baking study was designed as full factorial design with the three factors: ground/unground seeds, long/short cooking time, long/short swelling time according to typical German poppy seed cake baking recipes. The poppy seed was not washed or otherwise treated to reduce the opiate content. The original content in the seed was $270 \mathrm{mg} / \mathrm{kg}$ of morphine. The highest recovery in unground seeds was $50 \%$, while the lowest recovery for ground seeds was $16 \%$. From the factors studied, only grinding had a statistically significant influence on the alkaloid content (see full Analysis of Variance results in supporting information for Sproll et al., 2006). In the meantime, we have replicated the results of Sproll et al. (2006), also providing a comparison between raw and baked poppy cake dough (Figure 1).

Finally, our results were independently confirmed on a technical scale by the German Baking Agent Institute, which reported tests of fine bakery products containing poppy seeds from commercial bakeries. Production stage controls have shown that the morphine content decreases significantly because of crushing and intensive heating of the poppy seed. In the finished convenience products, morphine was either no longer detectable or only present in comparatively small amounts (Kniel, 2006). It must be also considered that poppy seeds only truly develop their nutty flavor after crushing, blanching and baking, all of which reduce the alkaloid content. Indirect 


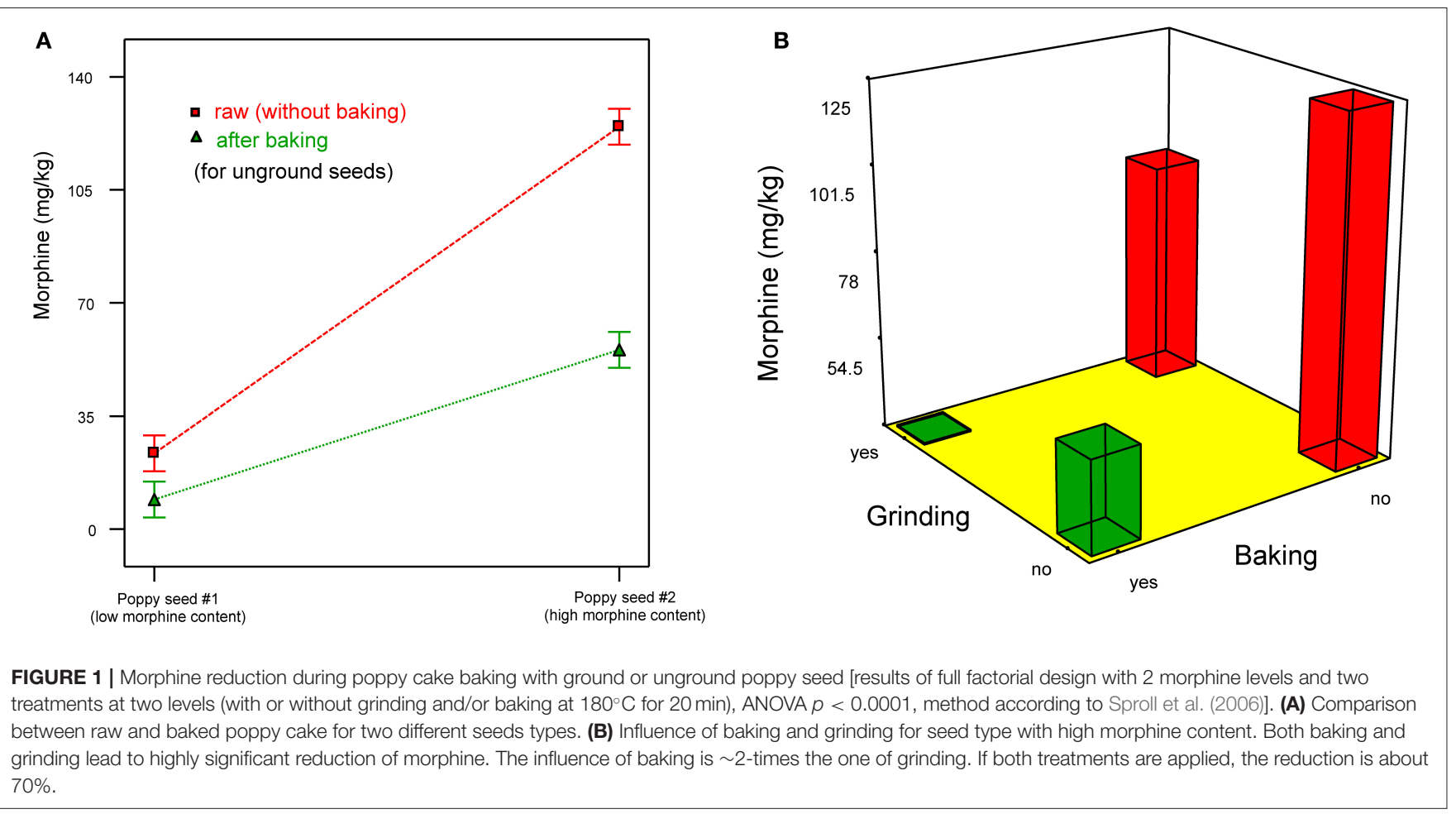

TABLE 1 | Changes in morphine content of poppy seed foods during processing according to literature data.

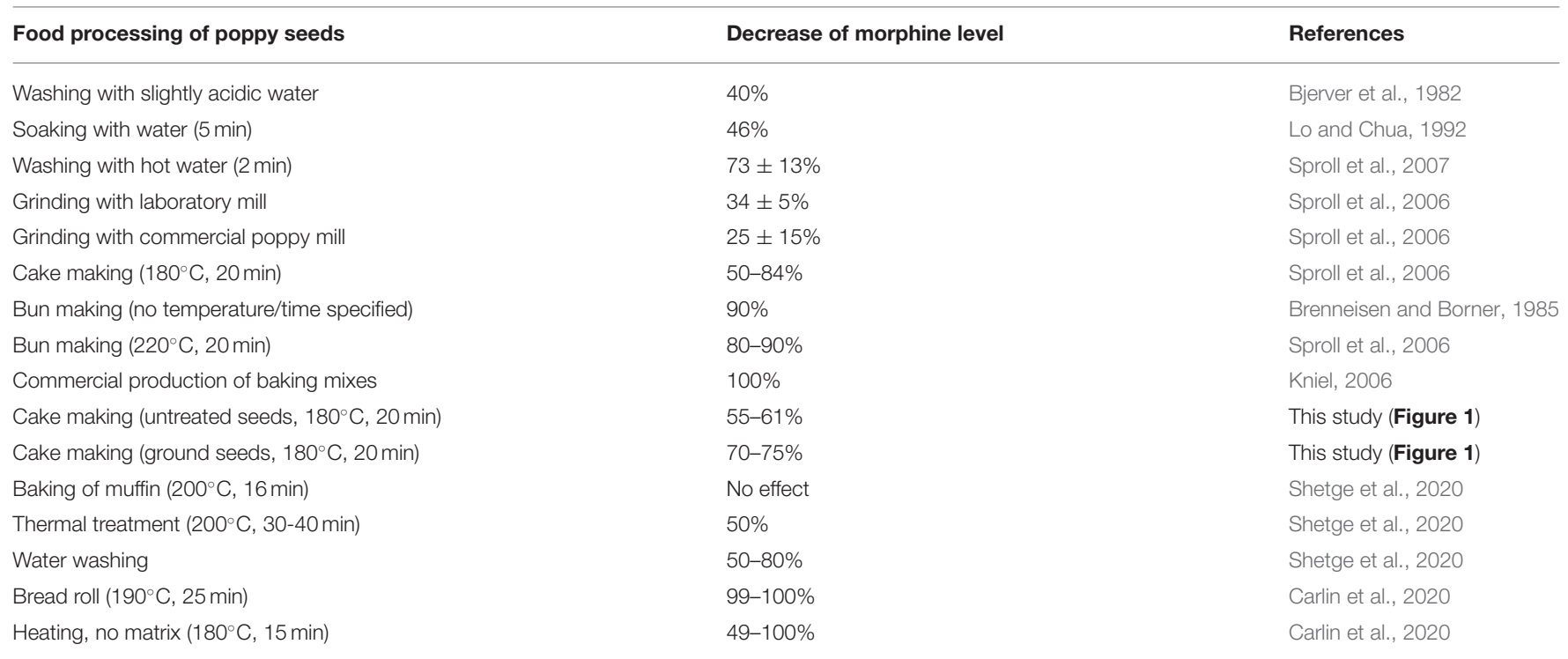

evidence of the feasibility of measures to reduce the opium alkaloid content of food products is provided by the notable reduction of the amounts in commercial products in Germany, since awareness about the problem had been raised in 2005 (Lachenmeier et al., 2010).

For all these reasons, we believe that the literature comprehensively shows that a variety of food processing measures including baking is indeed reducing the opium alkaloid amount (Table 1), and that the result of the U.S.
FDA must be considered as outlier, possibly to be explained by the model experiment leading to comparably low interior temperatures inside the muffin (Kleinmeier et al., 2021).

For the regulatory or toxicological assessment of poppy seeds and poppy seed-containing products, it has therefore to be taken into account that during the preparation of poppy seeds (grinding, baking, and heating) considerable amounts can be eliminated depending on various enzymatic (phenol oxidases) and non-enzymatic effects (Sproll et al., 2007). It must be 
reiterated from our 2006 study, that the same effects can also occur during laboratory analysis of poppy seeds so that alkaloidreducing steps such as grinding or heating should be avoided at this stage, which would lead to incorrect, non-reproducible results (Sproll et al., 2006).

In a recent review, Casado-Hidalgo et al. (2021) discussed the current and future perspectives of opium alkaloids in food. They concluded that there are several ways of action to control the levels of opium alkaloids in food products. For example, maximum limits in seeds or foods, selection of certain varieties of poppy plants with seeds for food purposes, good harvesting practices to minimize contamination and good processing practices to minimize the concentration of opium alkaloids. The selection of almost alkaloid-free varieties may be specifically promising to avoid the problem without need for further process controls (Kuntz et al., 2019).

Poppy seed buns are unlikely to pose a hazard to consumers because of the small amounts consumed and the extensive degradation of morphine through the baking process, assuming moderate amounts of morphine in the poppy seed. In Germany, poppy seed cake is likely to be the main source of poppy seed consumption. Nowadays, bakeries rarely make their own poppy seed filling in the cake-making process. Almost exclusively convenience poppy seed fillings are used, which according to the above mentioned studies contain only traces of opiates. Poppy seed cakes from bakeries are thus unlikely to represent a source of danger. However, the morphine content in poppy seed for direct

\section{REFERENCES}

Bjerver, K., Jonsson, J., Nilsson, A., Schuberth, J., and Schuberth, J. (1982). Morphine intake from poppy seed food. J. Pharm. Pharmacol. 34, 798-801. doi: 10.1111/j.2042-7158.1982.tb06228.x

Brenneisen, R., and Borner, S. (1985). Psychotrope Drogen IV. Zur Morphinalkaloidführung von Papaver somniferum und Papaver bracteatum [Psychotropic drugs. IV. The morphinan alkaloid content of Papaver somniferum and Papaver bracteatum] (in German). Pharm. Acta Helv. $60,302-310$.

Carlin, M. G., Dean, J. R., and Ames, J. M. (2020). Opium alkaloids in harvested and thermally processed poppy seeds. Front. Chem. 8:737. doi: $10.3389 /$ fchem.2020.00737

Casado-Hidalgo, G., Morante-Zarcero, S., Pérez-Quintanilla, D., and Sierra, I. (2021). Opium alkaloids in food products: current and future perspectives. Trends Food Sc. Technol. 108, 92-102. doi: 10.1016/j.tifs.2020.12.013

Eisenreich, A., Sachse, B., Gürtler, R., Dusemund, B., Lindtner, O., and Schäfer, B. (2020). What do we know about health risks related to thebaine in food? Food Chem. 309:125564. doi: 10.1016/j.foodchem.2019.125564

Kleinmeier, D., Pettengill, E., and Redan, B. W. (2021). Commentary: opium alkaloids in harvested and thermally processed poppy seeds. Front. Chem. 8:622488. doi: 10.3389/fchem.2020.622488

Kniel, B. (2006). Morphin in Backwaren. Fakten aus der Praxis contra Theorie der Risikobewertung [Morphine in baked goods. Facts from practice versus theory of risk assessment] (in German). BMI Aktuell 1/2006, 2-4.

Kuntz, M., Blum, H., Bock, V., Walch, S. G., Mahler, M., Lachenmeier, D. W., et al. (2019), Untersuchung des Thebain-Gehalts von morphinarmen Mohnsorten [Investigation of thebaine content of low morphine poppy cultivars] (in German). Lebensmittelchem 73:S039. doi: 10.1002/lemi.201951039 delivery to the consumer should be reduced to the lowest level technologically possible.

Besides the morphine content in food products, attention should be paid to other opium alkaloids in poppy seed, such as thebaine. Up to now, morphine was the main subject of risk assessment of opium alkaloids in poppy seed. However, the limited data concerning the toxic potential of thebaine indicate a higher acute toxicity than morphine (Eisenreich et al., 2020).

We agree that the data currently available is limited and further studies are necessary to enable an extensive hazard characterization. Detailed research on the fate of opium alkaloids during different processing steps in food production as well as research on the toxic potential of different opium alkaloids in poppy seed might be topics for future studies.

\section{AUTHOR CONTRIBUTIONS}

The idea for the manuscript was conceptualized by DL. MK and PG wrote the first draft of the article. DL revised the article draft. All authors have read and agreed to the published version of the manuscript.

\section{ACKNOWLEDGMENTS}

Constanze Sproll was acknowledged for her year-long standing in analyzing and evaluating opium alkaloids in foods.

Lachenmeier, D. W., Sproll, C., and Musshoff, F. (2010). Poppy seed foods and opiate drug testing-where are we today? Ther. Drug Monit. 32, 11-18. doi: 10.1097/FTD.0b013e3181c0eee0

Lo, D. S. T., and Chua, T. H. (1992). Poppy seeds: implications of consumption. Med. Sci. Law 32, 296-302. doi: 10.1177/002580249203200403

Shetge, S. A., Dzakovich, M. P., Cooperstone, J. L., Kleinmeier, D., and Redan, B. W. (2020). Concentrations of the opium alkaloids morphine, codeine, and thebaine in poppy seeds are reduced after thermal and washing treatments but are not affected when incorporated in a model baked product. J. Agric. Food Chem. 68, 5241-5248. doi: 10.1021/acs.jafc.0c01681

Sproll, C., Perz, R. C., Buschmann, R., and Lachenmeier, D. W. (2007). Guidelines for reduction of morphine in poppy seed intended for food purposes. Eur. Food Res. Technol. 226, 307-310. doi: 10.1007/s00217-006-0522-7

Sproll, C., Perz, R. C., and Lachenmeier, D. W. (2006). Optimized LC/MS/MS analysis of morphine and codeine in poppy seed and evaluation of their fate during food processing as a basis for risk analysis. J. Agric. Food Chem. 54, 5292-5298. doi: 10.1021/jf0608975

Conflict of Interest: The authors declare that the research was conducted in the absence of any commercial or financial relationships that could be construed as a potential conflict of interest.

Copyright (C) $2021 \mathrm{Kuntz}$, Golombek and Lachenmeier. This is an open-access article distributed under the terms of the Creative Commons Attribution License (CC BY). The use, distribution or reproduction in other forums is permitted, provided the original author(s) and the copyright owner(s) are credited and that the original publication in this journal is cited, in accordance with accepted academic practice. No use, distribution or reproduction is permitted which does not comply with these terms. 